Diabetologia (1994) 37: 889-896

\title{
Hypertriglyceridaemia in subjects with normal and abnormal glucose tolerance: relative contributions of insulin secretion, insulin resistance and suppression of plasma non-esterified fatty acids
}

\author{
C.D. Byrne ${ }^{1}$, N.J. Wareham ${ }^{2}$, D. C. Brown ${ }^{1}$, P.M.S. Clark ${ }^{1}$, L.J. Cox ${ }^{1}$, N. E. Day ${ }^{2}$, C. R. Palmer ${ }^{2}$, T. W.M. Wang ${ }^{1}$, \\ D.R.R. Williams ${ }^{2}$, C.N.Hales ${ }^{1}$ \\ 1 University Department of Clinical Biochemistry, Addenbrooke's Hospital, Cambridge, UK \\ ${ }^{2}$ Department of Community Medicine, Institute of Public Health, University of Cambridge, Cambridge, UK
}

Summary Although plasma insulin and triglyceride concentrations are positively correlated in many studies, the relationships between insulin resistance, insulin secretion and hypertriglyceridaemia remain unclear. To study these associations, subjects between the ages of 40 and 64 were randomly selected from a general practice register and invited to attend for a standard oral glucose tolerance test for measurement of insulin, triglyceride and non-esterified fatty acid concentrations. The study comprised 1122 subjects who were not previously known to have diabetes and who completed the test. Using the World Health Organisation criteria, 51 subjects were classified to have non-insulin-dependent diabetes mellitus, 188 had impaired glucose tolerance and 883 subjects had normal glucose tolerance. Triglyceride concentrations in subjects with glucose intolerance were elevated compared to those in control subjects, even after adjustment for age, obesity and gender $(p<0.001$ for subjects with diabetes and $p<0.01$ for those with impaired glucose tolerance compared to normal subjects). In separate multiple regression analyses for males and females, the most important determinants of the plasma triglyceride concentration were the area under the non-esterified fatty acid suppression curve ( $p<0.001$ in both genders) and the waist-hip ratio $(p<0.001$ for men and $<0.01$ for women). The fasting insulin concentration was independently associated with triglyceride concentration in women only $(p<0.01)$. The most important determinant of the area under the non-esterified fatty acid suppression curve in men was the 30-min insulin increment, a measure of insulin secretion, $(p<0.001)$ whereas for women age $(p<0.001)$ and the body mass index $(p<0.01)$ were the most important. [Diabetologia (1994) 37: 889-896]

Key words Non-insulin-dependent diabetes mellitus, impaired glucose tolerance, hypertriglyceridaemia, hyperinsulinaemia, non-esterified fatty acid.
The prevalence of ischaemic heart disease is increased 2-3 fold for subjects with diabetes mellitus $[1,2]$ and is the principal cause of morbidity and mortality for subjects with NIDDM [3,4]. Prospective epidemiological studies have shown that hypertrigly-

Received: 12 November 1993

and in revised form: 9 March 1994

Corresponding author: Professor C.N.Hales, University Department of Clinical Biochemistry, Addenbrooke's Hospital, Cambridge CB2 2SR, UK

Abbreviations: NIDDM, non-insulin-dependent diabetes mellitus; IGT, impaired glucose tolerance; NEFA, non-esterified fatty acid. ceridaemia, a common feature of diabetic dyslipidaemia [5], is associated with increased cardiovascular risk [6]. It is also closely linked with insulin resistance and hyperinsulinaemia, and a cluster of other metabolic abnormalities (the insulin resistance syndrome or syndrome X) [7]. Recently it has been shown that subjects with IGT $[8,9]$ or NIDDM [1013] have a relative insulin deficiency (as determined by decreased 30 -min insulin concentrations after an oral glucose challenge) compared to subjects with normal glucose tolerance. However, it is not known whether this relative deficiency is associated with hypertriglyceridaemia.

Insulin and NEFA are important regulators of VLDL production both in vitro [14-17] and in vivo 
Table 1. Baseline data by glucose intolerance category and gender

\begin{tabular}{llll}
\hline Male subjects & $\begin{array}{l}\text { New diabetes } \\
(23)\end{array}$ & $\begin{array}{l}\text { IGT } \\
(75)\end{array}$ & $\begin{array}{l}\text { Normal } \\
(129)\end{array}$ \\
\hline Age (years) & $58.4(5.8)^{\mathrm{f}}$ & $56.7(7.6)^{\mathrm{f}}$ & $52.9(8.2)$ \\
BMI $\left(\mathrm{kg} / \mathrm{m}^{2}\right)$ & $28.7(4.3)^{\mathrm{f}}$ & $27.2(3.2)^{\mathrm{e}}$ & $25.7(3.3)^{\mathrm{a}}$ \\
Waist-hip ratio & $0.96(0.05)^{\mathrm{cfh}}$ & $0.92(0.06)^{\mathrm{ce}}$ & $0.90(0.06)^{\mathrm{c}}$ \\
\hline Female subjects & New diabetes $^{(\mathrm{IGT}}$ & Normal \\
& $(28)$ & $(112)$ & $(181)$ \\
\hline Age (years) & $61.1(5.0)^{\mathrm{fi}}$ & $56.9(7.1)^{\mathrm{f}}$ & $52.6(7.8)$ \\
BMI $\left(\mathrm{kg} / \mathrm{m}^{2}\right)$ & $30.2(5.1)^{\mathrm{f}}$ & $28.2(6.2)^{\mathrm{f}}$ & $24.8(4.0)$ \\
Waist-hip ratio & $0.81(0.06)^{\mathrm{fg}}$ & $0.78(0.06)^{\mathrm{e}}$ & $0.76(0.05)$ \\
\hline
\end{tabular}

Results are presented as mean (SD)

Significance tests for comparisons of means

Male vs female within glucose category ${ }^{a} p<0.05 ;{ }^{b} p<0.01$; ${ }^{c} p<0.001$

New diabetes or IGT vs normal within gender ${ }^{d} p<0.05$; ${ }^{\mathrm{e}} p<0.01 ;{ }^{\mathrm{f}} p<0.001$

New diabetes vs IGT within gender ${ }^{\mathrm{g}} p<0.05 ;{ }^{\mathrm{h}} p<0.01$; ${ }^{\mathrm{i}} p<0.001$

[18]. While there is agreement that VLDL-triglyceride production is increased in NIDDM [19-21] there is disagreement concerning the mechanism. The aims of this study were to determine, in subjects with both normal and abnormal glucose tolerance: 1) whether differences in NEFA suppression during a standard oral glucose tolerance test were associated with changes in plasma triglyceride concentrations, and 2) whether insulin parameters predicted plasma NEFA concentrations.

\section{Subjects, materials and methods}

The subjects described here were studied as part of the first phase of a prospective study into the aetiology and pathogenesis of NIDDM being carried out in Ely, Cambridgeshire, UK. The sampling frame was constructed from the local general practice register and a letter of invitation was sent to a random selection of patients not previously known to have diabetes, between the ages of 40 and 64 years. Local ethical committee approval was obtained and patients gave their informed consent to participate in the study. Of the 1571 subjects invited $1156(74 \%)$ participated in the study. After a 10-h fast, subjects underwent a clinical examination which included a dietary and medical questionnaire, anthropometric measurements and a standard 75-g oral glucose tolerance test. Height, weight, waist and hip circumferences were measured without shoes and in light clothing. Waist circumference was measured at the mid-point between the inferior border of the costal margin and the anterior superior iliac crest and hip circumference at the level of the greater trochanters.

Subjects were given the equivalent of 75-g anhydrous glucose in $250 \mathrm{ml}$ water and venous blood samples were collected at baseline, and at 30 and $120 \mathrm{~min}$. Serum was immediately separated, kept on ice and stored at $-70^{\circ} \mathrm{C}$ within $4 \mathrm{~h}$. Plasma glucose was measured by a hexokinase method [22] and triglyceride measured using the RA 1000 (Bayer Diagnostics, Basingstoke, Hants., UK) with a standard enzymatic method. Plasma insulin was determined by two-site immunometric as- says with either ${ }^{125} \mathrm{I}$ or alkaline phosphatase labels [23, 24]. Insulin concentrations were measured in baseline, 30-min and 120-min samples. A measure of insulin secretion was calculated by dividing the difference between $30-\mathrm{min}$ insulin and fasting insulin concentrations by the 30 -min glucose concentration (the 30-min insulin increment). Plasma NEFA concentrations were determined enzymatically based on acyl-CoA synthetase activity (Boehringer Mannheim, Lewes, Sussex, UK). The resultant acyl-CoA is oxidised to yield hydrogen peroxide which is measured colorimetrically [25]. The assay had a between assay coefficient of variation of $10 \%$ at $0.40 \mathrm{mmol} / \mathrm{l}$ and $6 \%$ between 1.2 and $2.3 \mathrm{mmol} / \mathrm{l}$. NEFA concentrations were measured in baseline, 30-min and 120-min samples. The area under the NEFA suppression curve was also included in the analysis as a measure of both the fasting concentration and the suppression of NEFAs during the oral glucose tolerance test. This area was calculated as the area under the trapezium described by the NEFA measurements at time 0,30 and $120 \mathrm{~min}$ (units h. mmol/1).

The World Health Organisation criteria [26] were used to identify subjects with diabetes (fasting plasma glucose $>7.8 \mathrm{mmol} / \mathrm{l}$ or $2 \mathrm{~h}$ glucose $>11.1 \mathrm{mmol} / \mathrm{l})$, IGT (2-h glucose between $7.8-11.1 \mathrm{mmol} / \mathrm{l}$ ) and normal glucose tolerance (2-h glucose $<7.8 \mathrm{mmol} / \mathrm{l}$ ) (subsequently referred to as control subjects). Control subjects for this analysis represented a $35 \%$ sample of all subjects found to have normal glucose tolerance and were selected by random stratified sampling on the basis of their triglyceride concentration. There were no statistical differences in baseline characteristics of the control subjects in this analysis and the whole population of subjects with normal glucose tolerance.

\section{Statistical analysis}

The means of the baseline variables are presented in Tables 1 and 2 stratified by gender and glucose tolerance category. Arithmetic means (SD) are presented where the underlying variable is normally distributed and geometric mean (and 95\% confidence interval) where the distribution of a variable is skewed. Comparison of means between gender within each glucose tolerance category and between categories within each gender, was by the $Z$ test. The adjusted means (Table 3 ) were calculated using regression models separately for men and women, fitting each of the $\log$ transformed dependent variables with age, body mass index and waist-hip ratio in normal subjects. The mean residual was calculated in each category to give the amount by which the group mean should be corrected.

Comparison of the corrected mean values of the diabetes group and the IGT group with the control subjects was by the $\mathrm{Z}$ test. Pearson correlation coefficients (Table 4) were derived to show the relationship between variables (log transformed where necessary) stratified by glucose category (with IGT and diabetes considered together) and gender. Finally multiple regression models were derived separately for males and females to explain triglyceride concentrations and the NEFA area. The following variables were entered into the triglyceride model; age, body mass index, waist-hip ratio, fasting insulin, the 30-min insulin increment and the NEFA area. The same variables (excluding NEFA area) were entered into the NEFA area model. For each variable in the final model the standardised $\beta$ coefficient and its significance are given (Table 5). The overall $R^{2}$ may be interpreted as the proportion of the overall variability in the dependent variable that is explained by the model and is presented in an adjusted form to allow comparison between models that include different numbers of explanatory variables. 
Table 2. Biochemical data at 0,30 and 120 min during an oral glucose tolerance test

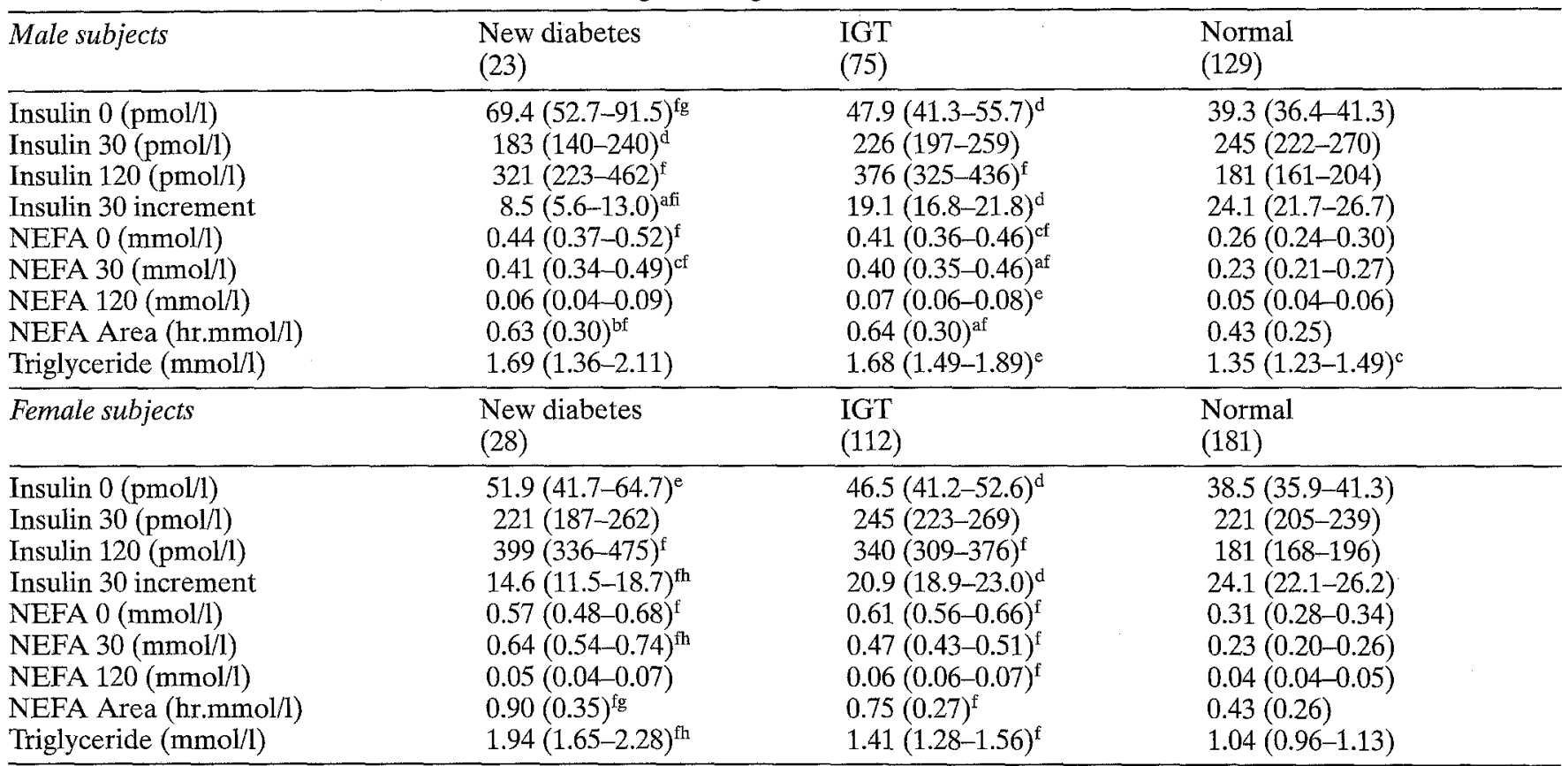

Geometric mean and $95 \%$ confidence interval for all variables except NEFA area which is expressed as mean (SD)

Significance tests for comparisons of means

Male vs female within glucose category ${ }^{\mathrm{a}} p<0.05,{ }^{\mathrm{b}} p<0.01,{ }^{\mathrm{c}} p<0.001$

New diabetes or IGT vs normal within gender ${ }^{\mathrm{d}} p<0.05,{ }^{\mathrm{e}} p<0.01,{ }^{\mathrm{f}} p<0.001$

New diabetes vs IGT within gender ${ }^{\mathrm{g}} p<0.05,{ }^{\mathrm{h}} p<0.01,{ }^{\mathrm{i}} p<0.001$

Table 3. Biochemical data after adjustment for age, sex, body mass index and waist-hip ratio

\begin{tabular}{llll}
\hline & $\begin{array}{l}\text { New diabetes } \\
(51)\end{array}$ & $\begin{array}{l}\text { IGT } \\
(187)\end{array}$ & $\begin{array}{l}\text { Normal } \\
(310)\end{array}$ \\
\hline Insulin 0 $(\mathrm{pmol} / \mathrm{l})$ & $49.9(42.8-58.2)^{\mathrm{c}}$ & $44.4(41.0-48.0)^{\mathrm{b}}$ & $38.9(37.0-40.8)$ \\
Insulin 30 (pmol/l) & $134(115-156)^{\mathrm{cf}}$ & $208(193-234)^{\mathrm{a}}$ & $237(222-252)$ \\
Insulin 120 (pmol/l) & $241(199-293)^{\mathrm{b}}$ & $210(194-227)^{\mathrm{b}}$ & $181(169-194)$ \\
Insulin 30 increment & $4.7(4.1-5.5)^{\mathrm{cf}}$ & $15.5(14.4-16.8)^{\mathrm{c}}$ & $24.1(22.5-25.8)$ \\
NEFA 0 $(\mathrm{mmol} / \mathrm{l})$ & $0.32(0.28-0.37)$ & $0.31(0.29-0.33)$ & $0.29(0.27-0.31)$ \\
NEFA 30 $(\mathrm{mmol} / 1)$ & $0.32(0.28-0.36)^{\mathrm{b}}$ & $0.27(0.25-0.30)^{\mathrm{a}}$ & $0.23(0.21-0.25)$ \\
NEFA 120 (mmol/l) & $0.05(0.04-0.06)$ & $0.05(0.04-0.05)$ & $0.05(0.04-0.05)$ \\
NEFA area (hr.mmol/1) & $0.90(0.35)^{\mathrm{cd}}$ & $0.75(0.27)^{\mathrm{c}}$ & $0.43(0.26)$ \\
Triglyceride (mmol/l) & $1.56(1.34-1.82)^{\mathrm{c}}$ & $1.33(1.24-1.43)^{\mathrm{b}}$ & $1.16(1.09-1.24)$ \\
\hline
\end{tabular}

Geometric mean and $95 \%$ confidence interval for all variables except NEFA area which is expressed as mean (SD)

Significance tests for comparisons of means

New diabetes or IGT vs normal ${ }^{\mathrm{a}} p<0.05,{ }^{\mathrm{b}} p<0.01,{ }^{\mathrm{c}} p<0.001$

New diabetes vs IGT ${ }^{\mathrm{d}} p<0.05,{ }^{\mathrm{e}} p<0.01,{ }^{\mathrm{f}} p<0.001$

\section{Results}

In this study 51 subjects were found to have previously undiagnosed diabetes and 188 had IGT. Complete data is available on all subjects with diabetes, 187 subjects with IGT and 310 control subjects (Table 1). Subjects with IGT and NIDDM were older and more obese than the control subjects. In subjects with normal glucose tolerance, geometric mean plasma triglyceride concentration was significantly lower for women $(1.04 \mathrm{mmol} / 1,95 \%$ confidence interval $0.96-1.13 \mathrm{mmol} / \mathrm{l})$ than for men $(1.35 \mathrm{mmol} / 1,95 \%$ confidence interval $1.23-1.49 \mathrm{mmol} / \mathrm{l}, p<0.001)$. For subjects with NIDDM, however, the mean triglyceride concentration was higher in women $(1.94 \mathrm{mmol} / \mathrm{l}$, $95 \%$ confidence interval $1.65-2.28 \mathrm{mmol} / \mathrm{l}$ ) than in men $(1.69 \mathrm{mmol} / 1,95 \%$ confidence interval $1.36-$ $2.11 \mathrm{mmol} / \mathrm{l})$ although the difference was not statistically significant.

NEFA area was increased in subjects with NIDDM compared to control subjects ( $p<0.001$ both sexes) although the increase in women was greater. In both sexes NEFA area levels in subjects with IGT were higher than control subjects $(p<0.001)$ and in women with IGT the mean area was lower than for female subjects with NIDDM $(p<0.05)$ (Table 2$)$. There was 
Table 4. Pearson correlation coefficients between variables in subjects with normal and abnormal glucose tolerance by gender

Subjects with normal glucose tolerance

\begin{tabular}{|c|c|c|c|c|c|c|c|c|c|}
\hline & \multicolumn{9}{|c|}{ Male subjects } \\
\hline & Age & BMI & WHR & $\begin{array}{l}\text { NEFA } \\
\text { area }\end{array}$ & TG & $\mathrm{I}-0$ & $\mathrm{I}-30$ & $\mathrm{I}-120$ & $\begin{array}{l}\text { Insulin } \\
\text { increment }\end{array}$ \\
\hline BMI & 0.10 & & $0.61^{\mathrm{c}}$ & 0.09 & $0.38^{\mathrm{c}}$ & $0.47^{\mathrm{c}}$ & $0.39^{c}$ & $0.27^{\mathrm{b}}$ & $0.33^{c}$ \\
\hline WHR & $0.26^{\mathrm{c}}$ & $0.28^{c}$ & & 0.08 & $0.41^{\mathrm{c}}$ & $0.39^{c}$ & $0.33^{c}$ & $0.28^{\mathrm{b}}$ & $0.26^{\mathrm{b}}$ \\
\hline NEFA area & $0.34^{c}$ & $0.19^{\mathrm{a}}$ & 0.13 & & $0.32^{c}$ & -0.02 & -0.14 & 0.06 & $-0.21^{\mathrm{a}}$ \\
\hline Insulin 30 & 0.02 & $0.27^{\mathrm{c}}$ & $0.25^{\mathrm{c}}$ & 0.07 & $0.23^{b}$ & $0.43^{\mathrm{c}}$ & & $0.27^{\mathrm{b}}$ & $0.95^{\circ}$ \\
\hline Insulin 120 & $0.20^{\mathrm{b}}$ & $0.27^{\mathrm{a}}$ & $0.22^{\mathrm{b}}$ & $0.38^{\mathrm{c}}$ & $0.28^{\mathrm{c}}$ & $0.42^{\mathrm{c}}$ & $0.37^{\mathrm{c}}$ & & $0.20^{\mathrm{a}}$ \\
\hline \multirow[t]{2}{*}{ Insulin increment } & -0.06 & 0.14 & 0.12 & -0.04 & 0.11 & $0.21^{\mathrm{b}}$ & $0.92^{c}$ & $0.20^{\mathrm{b}}$ & \\
\hline & \multicolumn{9}{|c|}{ Female subjects } \\
\hline
\end{tabular}

Subjects with abnormal glucose tolerance

\begin{tabular}{|c|c|c|c|c|c|c|c|c|c|}
\hline & \multicolumn{9}{|c|}{ Male subjects } \\
\hline & Age & BMI & WHR & $\begin{array}{l}\text { NEFA } \\
\text { area }\end{array}$ & $\mathrm{TG}$ & $\mathrm{I}-0$ & $\mathrm{I}-30$ & $\mathrm{I}-120$ & $\begin{array}{l}\text { Insulin } \\
\text { increment }\end{array}$ \\
\hline BMI & -0.07 & & $0.46^{\mathrm{c}}$ & -0.02 & 0.12 & $0.57^{\mathrm{c}}$ & $0.38^{c}$ & $0.38^{\mathrm{c}}$ & $0.22^{\mathrm{a}}$ \\
\hline WHR & 0.15 & $0.44^{\mathrm{c}}$ & & -0.08 & $0.28^{b}$ & $0.46^{\mathrm{c}}$ & $0.23^{\mathrm{a}}$ & $0.37^{\mathrm{c}}$ & 0.06 \\
\hline NEFA area & $0.22^{\mathrm{a}}$ & 0.00 & 0.07 & & 0.12 & -0.01 & -0.08 & 0.12 & -0.13 \\
\hline Insulin 30 & -0.09 & $0.48^{\mathrm{c}}$ & $0.27^{\mathrm{b}}$ & -0.08 & $0.30^{\circ}$ & $0.71^{c}$ & & $0.66^{\mathrm{c}}$ & $0.86^{\mathrm{c}}$ \\
\hline Insulin 120 & -0.07 & $0.44^{\mathrm{c}}$ & $0.36^{\mathrm{c}}$ & 0.11 & $0.35^{\mathrm{c}}$ & $0.68^{c}$ & $0.64^{c}$ & & $0.56^{\mathrm{c}}$ \\
\hline \multirow[t]{2}{*}{ Insulin increment } & -0.15 & $0.24^{\mathrm{b}}$ & 0.07 & -0.15 & 0.13 & 0.37 & 0.87 & 0.43 & \\
\hline & \multicolumn{9}{|c|}{ Female subjects } \\
\hline
\end{tabular}

Significance levels: ${ }^{\mathrm{a}} p<0.05,{ }^{\mathrm{b}} p<0.01,{ }^{\mathrm{c}} p<0.001$

All variables normalised by logarithmic transformation except age, body mass index (BMI), waist-hip ratio (WHR) and NEFA area.

TG, Triglyceride

Table 5. Multiple regression models for NEFA area and triglyceride in male and female subjects

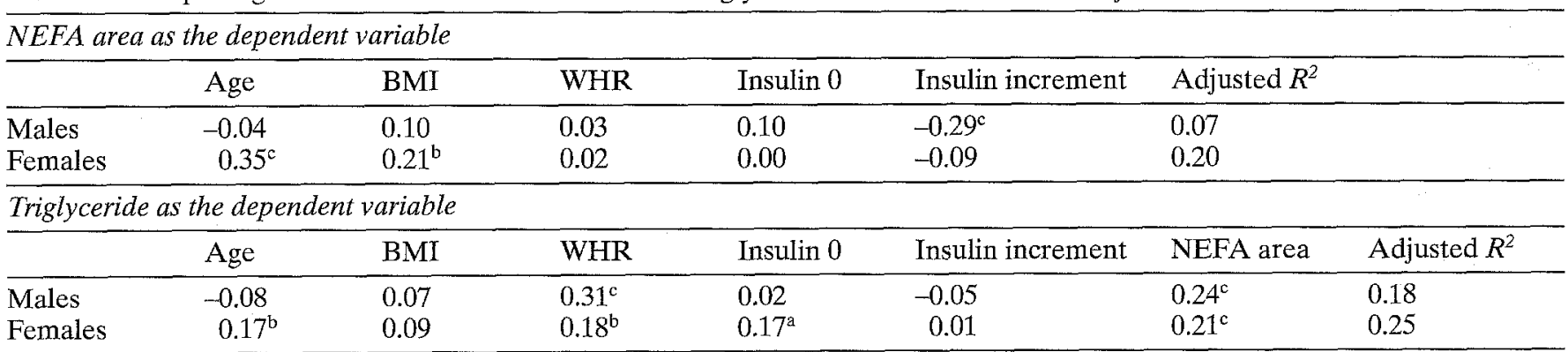

Significance of standardised $\beta$ coefficient ${ }^{\mathrm{a}} p<0.05,{ }^{\mathrm{b}} p<0.01,{ }^{\mathrm{c}} p<0.001$

Results are standardised $\beta$ coefficient and significance, and adjusted $R^{2}$ for each model

WHR, Waist-hip ratio; BMI, body mass index

a significant elevation of NEFA area in women compared to men both for subjects with NIDDM $(p<0.01)$ and IGT $(p<0.05)$. Geometric mean fasting and 2-h insulin concentrations were increased for men and for women with IGT and NIDDM compared to control subjects. The $30-\mathrm{min}$ insulin concentrations were lower only for men with NIDDM compared to control subjects $(p<0.05)$. The $30-\mathrm{min}$ insulin incre- ment in subjects with NIDDM was significantly lower than for control subjects ( $p<0.001$ both sexes) and also lower than for subjects with IGT $(p<0.001$ in males and $p<0.01$ in females). In subjects with IGT this measure was lower than that in control subjects ( $p<0.05$ both sexes).

After adjustment for age, sex, body mass index and the waist-hip ratio, 30-min insulin concentra- 
tions were lower for subjects with IGT and NIDDM compared to control subjects (IGT vs normal subjects, $\quad p<0.05$; NIDDM vs normal subjects, $p<0.001$ ). Fasting and 120 -min insulin concentrations were increased in subjects with NIDDM and IGT compared to normal subjects (Table 3 ). The 30min insulin increment was significantly lower in subjects with NIDDM and IGT than control subjects. NEFA area increased as glucose tolerance deteriorated (IGT and NIDDM vs control subjects, $p<0.001$ ) and triglyceride concentrations also increased with deteriorating glucose tolerance (IGT vs control subjects, $p<0.01$ and NIDDM vs control subjects, $p<0.001$ ).

Table 4 shows the Pearson correlation coefficients between anthropometric and metabolic variables, log transformed where necessary, and stratified by gender and glucose tolerance category. For these analyses subjects with IGT and NIDDM were combined into one group of subjects with abnormal glucose tolerance. There was a correlation between NEFA area and triglyceride concentration for subjects of either sex with normal glucose tolerance (both sexes $p<0.001$ ) and abnormal glucose tolerance (male $p>0.05$ and female $p<0.01$ ). The waisthip ratio was significantly positively correlated with plasma triglyceride for subjects with normal (both sexes $p<0.001$ ) or abnormal glucose tolerance (males $p<0.01$, females $p<0.001$ ). In all subjects fasting insulin concentrations were significantly associated with triglyceride concentrations.

In the multiple regression models (Table 5) the 30min insulin increment had a strong negative independent association with NEFA area in men $(p<0.001)$. In women, although the direction of the association between the 30-min insulin increment and NEFA area was the same (standardised $\beta$ coefficient -0.09 ), this did not reach statistical significance. For women, age $(p<0.001)$ and the body mass index $(p<0.01)$ had the strongest association with NEFA area. The fasting insulin concentration was not independently associated with NEFA area in either sex.

The waist-hip ratio and NEFA area both had a strong positive independent association with triglyceride concentration in male and female subjects. Age and the fasting insulin concentration were independently associated with triglyceride concentration in women only.

\section{Discussion}

The results of this study show that the NEFA area was increased in subjects with abnormal glucose tolerance, and that the NEFA area and the waist-hip ratio had the strongest independent associations with plasma triglyceride concentrations in subjects with either normal or abnormal glucose tolerance. In vivo, plasma NEFA concentrations are largely determined by the action of insulin to suppress adipocyte lipolysis, and in the physiological state insulin suppresses hormone sensitive lipase $[27,28]$ and promotes re-esterification of NEFA [29]. Plasma NEFA concentrations may be important determinants of plasma triglyceride concentrations since the rate of supply of NEFA to the liver is a major factor controlling hepatic triglyceride secretion $[16,30]$. Furthermore, hepatic triglyceride synthesis is controlled by the availability of NEFA substrate and by the coordinate regulation of the activities of phosphatidate phosphohydrolase and diacylglycerol acyltransferase. Both of these enzymes are stimulated by NEFA [31,32] and it has been shown that phosphatidate phosphohydrolase activity is increased in diabetes [33]. Consequently failure to adequately suppress NEFA release into the plasma could have important consequences for VLDL production and plasma triglyceride concentration.

Although insulin is an important factor in the suppression of NEFA release from adipocytes, it is uncertain whether NEFA suppression is affected by insulin resistance, hyperinsulinaemia or altered insulin secretion (or a combination). It was our intention to determine whether any of the insulin parameters usefully predicted plasma NEFA concentrations. Laakso [34] showed that in subjects with normal and abnormal glucose tolerance, fasting insulin concentration was the best marker of insulin resistance as determined by whole body glucose uptake using the euglycaemic hyperinsulinaemic clamp technique. The 120min insulin concentrations during the oral glucose tolerance test were a reliable marker of insulin resistance for subjects with normal glucose tolerance but not for subjects with abnormal glucose tolerance. It was for this reason that we included the fasting insulin concentration as the measure of insulin resistance in the multiple regression models and excluded the 120 -min insulin. In recent studies the $30-\mathrm{min}$ insulin concentration during the oral glucose tolerance test has been shown to be a good marker of insulin secretion as determined by 3 -min insulin concentrations during an intravenous glucose tolerance test [35]. The 30-min insulin increment, as defined in this paper is superior to the $30-\mathrm{min}$ insulin concentration as an index of insulin secretion (D. I. W. Phillips - personal communication) and was therefore included in the multiple regression models as the best available measure of insulin secretion in an oral glucose tolerance test.

The results from this study showed that in men with normal glucose tolerance, the NEFA area was negatively correlated with the 30-min insulin increment, but not with either fasting or 120-min insulin. In women there was also a negative, but weaker and not statistically significant, correlation between the 30-min insulin increment and the NEFA area. There 
was a stronger correlation in women than in men between 120-min insulin concentration and NEFA area. This result suggests that there are gender differences between the relative importance of insulin secretion and insulin resistance and their effects on NEFA suppression. For subjects with abnormal glucose tolerance the direction of each of these correlations was the same but none of the correlations were statistically significant, which may be attributed to the smaller number of subjects in this group.

As there were apparent gender differences in factors determining NEFA suppression, the multiple regression models for NEFA area and triglyceride concentrations were analysed separately by gender. Subjects with normal and abnormal glucose tolerance were grouped together as the Pearson correlation coefficients showed that relationships were generally in the same direction within and between glucose tolerance groups and therefore it was unlikely that false associations would be observed by studying glucose tolerance categories together. There was a strong negative independent association between the 30 -min insulin to glucose ratio and NEFA area in men and a weaker negative association in women. The fasting insulin concentration was not independently associated with NEFA area for either sex. Together these results suggest that insulin secretion is an important factor determining plasma NEFA concentrations, particularly for men, whereas insulin resistance was an important factor determining plasma NEFA concentrations only for women with normal glucose tolerance.

The data show a strong positive correlation between fasting insulin and plasma triglyceride concentrations in all subjects, which concurs with the findings of other studies [36-38]. This observation has been taken to imply that either hyperinsulinaemia or insulin resistance (or both) are causative in raising plasma triglyceride concentrations. However, in this study, when the effects of other covariates are taken into account, the association between fasting insulin and triglyceride is only weakly significant and is restricted to women. This finding, together with the knowledge that hyperinsulinaemia in subjects with insulinomas is not associated with hypertriglyceridaemia [39], suggests that it is unlikely that hyperinsulinaemia per se is responsible for causing hypertriglyceridaemia [40].

Lipoprotein lipase is an insulin-dependent enzyme the activity of which is decreased in obesity [41] and NIDDM [42, 43], but which may be increased by improved metabolic control [44-46]. Activity of this enzyme is important in the clearance of postprandial triglyceride-rich lipoproteins from the circulation and reduced hepatic uptake or reduced clearance of triglyceride-rich lipoproteins may contribute to hypertriglyceridaemia in subjects with abnormal glucose tolerance [43]. The association in this study between fasting plasma insulin and plasma triglyceride concentrations (in women only) may be a consequence of insulin resistance with decreased lipoprotein lipase activity. All the subjects in this study were fasting and the consequence of impaired lipoprotein lipase activity on clearance of triglyceride-rich lipoproteins may be more important in the postprandial state.

Previous studies have demonstrated a strong association between intra-abdominal fat and the waisthip ratio [47]. Therefore, the observed association between the waist-hip ratio and triglyceride may be indicative of an underlying relationship between intraabdominal fat deposition and triglyceride concentration. The finding that intra-abdominal adipocytes have a higher sensitivity to the stimulation of lipid mobilisation processes, and that the anti-lipolytic effect of insulin on these cells is less than on the subcutaneous adipocytes [48], may provide a biologically plausible explanation for these observations.

For subjects with normal glucose tolerance, mean plasma triglyceride concentrations were lower for women than for men which may partially account for the lower risk of ischaemic heart disease for women than for men with normal glucose tolerance. Elevated plasma triglyceride concentrations are associated with small dense LDL particles, decreased plasma HDL levels and increased cardiovascular risk. The waist-hip ratio was lower for women than for men, but insulin and fasting NEFA concentrations were similar for both sexes. Recently it has been suggested that, for subjects with normal glucose tolerance, suppression of NEFA was greater for women than for men during an oral glucose tolerance test [49]. In contrast, our data indicate that for subjects with normal glucose tolerance the impact of gender on NEFA is small but that gender differences become marked as glucose tolerance deteriorates. In parallel with the increased NEFA area there was a more marked increase in plasma triglyceride for women than for men with abnormal glucose tolerance. This effect may contribute to the higher relative cardiovascular risk observed in women compared to men with NIDDM $[50,51]$.

In conclusion, these results show that increased NEFA concentrations are an important determinant of triglyceride concentrations. Increasing obesity and age (for women) and deteriorating insulin secretion (for men and women) act to increase plasma NEFA concentration. The waist-hip ratio is not associated with plasma NEFA concentrations and would appear to affect triglyceride concentration through a different mechanism. We suggest that increased plasma NEFAs are an important factor contributing to hypertriglyceridaemia and may be associated with the increased cardiovascular risk for subjects with abnormal glucose tolerance. Furthermore, the marked increase in plasma NEFA and plasma triglyceride 
concentrations for women with NIDDM may partly explain why NIDDM is a stronger cardiovascular risk factor in women than in men.

Acknowledgements. This study was supported by grants from the British Diabetic Association and Medical Research Council, Corda and Lilley Research Laboratories. C.D.B. was a Medical Research Council Training Fellow. The technical assistance of R.Beck, T.Elsey, N.D.Martensz, R.McLeish, B.Mission, M.Sheldon and A.F.M.Tullock is gratefully acknowledged. We would like to thank Dr. B.Cox, J.M.Lipscombe, M.Quinn, S.Farmer, L.Koncewicz and $H$. Shanassy for their assistance in the field work and data entry. Finally we are grateful to all the volunteers who participated in the study and to Dr. J. Shackleton and his colleagues at the St Mary's Street Surgery, Ely.

\section{References}

1. Kannel WB, McGee DL (1979) Diabetes and cardiovascular disease. The Framingham study. J Am Med Soc 241: 2035-2038

2. Assman G, Schultz H (1988) The prospective cardiovascular Münster (PROCAM) study: prevalence of hyperlipidemia in persons with hypertension and/or diabetes mellitus and the relationship to coronary heart disease. Am Heart J 116: 1713-1724

3. Uusitupa M, Siitonen O, Aro A, Pyörälä K (1985) Prevalence of coronary heart disease, left ventricular failure and hypertension in middle-aged, newly diagnosed type 2 (non-insulin-dependent) diabetic subjects. Diabetologia 28: $22-27$

4. Stern MP, Haffner SM (1991) Dyslipidemia in type II diabetes. Diabetes Care 14: 1144-1159

5. Dunn FL (1990) Hyperlipidaemia in diabetes mellitus. Diabetes Metab Rev 6: 47-61

6. Gotto AM (1992) Hypertriglyceridemia: risks and perspectives. Am J Cardiol 70: $19 \mathrm{H}-25 \mathrm{H}$

7. Reaven GM (1988) The role of insulin resistance in human disease. Diabetes 37: 1595-1607

8. Williams DRR, Byrne C, Clark PMS et al. (1991) Raised proinsulin as early indicator of $\beta$ cell failure. BMJ 303: $95-$ 96

9. Davies MJ, Rayman G, Gray IP, Day IL, Hales CN (1993) Insulin deficiency and increased plasma concentration of intact and 32/33 split proinsulin in subjects with impaired glucose tolerance. Diabet Med 10: 313-320

10. Lillioja S, Mott DM, Howard BV et al. (1988) Impaired glucose tolerance as a disorder of insulin action. $\mathrm{N}$ Engl J Med 318: 1217-1225

11. Temple RC, Carrington CA, Luzio SD et al (1989) Insulin deficiency in non-insulin dependent diabetes. Lancet I: 293-295

12. Banerji MA, Lebovitz HE (1989) Insulin sensitive and insulin resistant variants in NIDDM. Diabetes 38: 784-792

13. Davies MJ, Metcalfe IP, Gray JL, Day JL, Hales CN (1993) Insulin deficiency rather than hyperinsulinaemia in newly diagnosed diabetes mellitus. Diabet Med 10: 305-312

14. Durrington PN, Newton S, Weinstein DB, Steinberg D (1982) Effects of insulin and glucose on very low density lipoprotein triglyceride secretion by cultured rat hepatocytes. J Clin Invest 70: 63-73

15. Pullinger CR, North JD, Teng BB, Rifici VA, Ronhild de Brito AE, Scott J (1989) The apolipoprotein gene is constitutively expressed in Hep G2 cells: regulation of secretion by oleic acid, albumin and insulin, and measurement of mRNA half life. J Lipid Res 30: 1065-1077

16. Byrne CD, Brindle NPJ, Wang TWM, Hales CN (1991) Interaction of non esterified fatty acid and insulin in control of triacylglycerol secretion by Hep G2 cells. Biochem J 280: 99-104

17. Byrne CD, Wang TWM, Hales CN (1992) Control of Hep G2 cell triacylglycerol and apolipoprotein-B synthesis and secretion by polyunsaturated non esterified fatty acids and insulin. Biochem J 288: 101-107

18. Reaven GM, Chen YD (1988) Role of insulin in regulation of lipoprotein metabolism in diabetes. Diabetes Metab Rev 4: 639-652

19. Kissebah AH, Alfarsi S, Evans DJ, Adams PW (1982) Integrated regulation of very low density lipoprotein triglyceride and apolipoprotein-B kinetics in non-insulin dependent diabetes mellitus. Diabetes 31: 217-225

20. Abrams JJ, Ginsberg H, Grundy SM (1982) Metabolism of cholesterol and triglycerides in non-ketotic diabetes mellitus. Diabetes 31: 903-910

21. Ginsberg HN (1991) Lipoprotein physiology in non diabetic and diabetic states. Diabetes Care 14: 839-855

22. Kunst A, Draeger B, Ziegenhorn J (1983) UV-methods with hexokinase and glucose 6-phosphate dehydrogenase. In: Bergmeyer HU (ed) Methods of enzymatic analysis, Vol VI. Weinheim Verlag Chemie, Deerfield, pp 163-172

23. Sobey WJ, Beer SF, Carrington CA et al. (1989) Sensitive and specific two site immunoradiometric assays for human insulin, proinsulin, 65-66 split and 32-33 split proinsulins. Biochem J 260: 535-541

24. Alpha B, Cox L, Crowther N, Clark PMS, Hales CN (1992) Sensitive amplified immunoenzymometric assays (IEMA) for human insulin and intact proinsulin. Eur J Clin Chem Clin Biochem 30: 27-32

25. Shimizu S (1980) Enzymatic determination of serum-free fatty acids: a colorimetric method. Anal Biochem 107: 193-198

26. WHO study group (1985) Diabetes mellitus. Technical report series No 727. WHO, Geneva

27. Weiland D, Mondon CE, Reaven GM (1980) Evidence for multiple causality in the development of diabetic hypertriglyceridemia. Diabetologia 18: 335-340

28. Yki-Jarvinen H, Taskinen M-R (1988) Interrelationships among insulin's lipolytic and glucoregulatory effects and plasma triglycerides in non-diabetic and diabetic patients with endogenous hypertriglyceridemia. Diabetes 37: 12711279

29. Coppack SW, Evans RD, Fisher RM et al. (1992) Adipose tissue metabolism in obesity: lipase action in vivo before and after a mixed meal. Metabolism 41: 264-272

30. Kissebah AH, Adams PW, Wynn V (1974) Inter-relationships between insulin secretion and plasma free fatty acid and triglyceride transport kinetics in maturity onset diabetes and the effect of phenethylbiguanide (phenformin). Diabetologia 10: 119-130

31. Cascales C, Mangiapane EH, Brindley DN (1984) Oleic acid promotes the activation and translocation of phosphatidate phosphohydrolase from the cytosol to particulate fractions of isolated rat hepatocytes. Biochem J 219: 911-916

32. Haagsman HP, Van Golde LMG (1981) Synthesis and secretion of very low density lipoproteins by isolated rat hepatocytes in suspension: role of diacylglycerol acyltransferase. Arch Biochem Biophys 208: 395-402

33. Pittner RA, Fears R, Brindley DN (1985) Effects of cyclic AMP glucocorticoids and insulin on the activities of phosphatidate phosphohydrolase, tyrosine aminotransferase and glycerol kinase in isolated rat hepatocytes in relation 
to the control of triacylglycerol synthesis and gluconeogenesis. Biochem J 255: 455-462

34. Laakso M (1993) How good a marker is insulin level for insulin resistance? Am $J$ Epidemiol 137: 959-965

35. Phillips DIW, Clark PM, Hales CN, Osmond C (1994) Understanding oral glucose tolerance: comparison of glucose or insulin measurements during the oral glucose tolerance test with specific measurements of insulin resistance and insulin secretion. Diabet Med 11: 286-292

36. Reaven GM, Greenfield MS (1981) Diabetic hypertriglyceridemia: evidence for three clinical syndromes. Diabetes 30: $66-75$

37. Tobey TA, Greenfield MS, Kraemer F, Reaven GM (1981) Relationship between insulin resistance, insulin secretion, very low density lipoprotein kinetics and plasma triglyceride levels in normotriglyceridemic man. Metabolism 30: 165-171

38. Steiner G, Haynes FJ, Yoshino G, Vranic M (1982) Hyperinsulinemia and in vivo very low density lipoprotein triglyceride kinetics. Am J Physiol 246: E187--E192

39. O'Brien T, Young WF, Palumbo PJ, O'Brien PC, Service FJ (1993) Hypertension and dyslipidemia in patients with insulinoma. Mayo Clin Proc 68: 141-146

40. Salomaa VV, Tuomilehto J, Jauhiainen M et al. (1992) Hypertriglyceridaemia in different degrees of glucose intolerance in a Finnish population-based study. Diabetes Care 15: $657-665$

41. Eckel RH (1987) Adipose tissue lipoprotein lipase. In: Borensztajn J (ed) Lipoprotein lipase. Evener, Chicago, pp 79-132

42. Nikkila EA (1984) Plasma lipid and lipoprotein abnormalities in diabetes. In: Jarrett RJ (ed) Diabetes and heart disease. Elsevier, Amsterdam, pp 133-167
43. Eckel RH (1989) Lipoprotein lipase. A multifunctional enzyme relevant to common metabolic diseases. $\mathrm{N}$ Engl $\mathrm{J}$ Med 320: 1060-1068

44. Brunzell JD, Porte D, Bierman EL (1975) Reversible abnormalities in post heparin lipolytic activity during the late phase of release in diabetes mellitus (post heparin lipolytic activity in diabetes). Metabolism 24: 1123-1137

45. Pykolisto OJ, Smith PH, Brunzell JD (1975) Determinants of human adipose tissue lipoprotein lipase: effect of diabetes and obesity on basal- and diet-induced activity. J Clin Invest 56: 1108-1117

46. Taskinen MR, Beltz WF, Harper I et al. (1986) The effect of non insulin-dependent diabetes mellitus on VLDL triglyceride and VLDL apoB metabolism: studies before and after sulphonylurea therapy. Diabetes 35: 1268-1277

47. Ashwell M, Cole TJ, Dixon AK (1985) Obesity: new insights into the anthropometric classification of fat distribution shown by computed tomography. BMJ 290: 1692-1694

48. Mắrin P, Andersson B, Ottosson M et al (1992) The morphology and metabolism of intra-abdominal adipose tissue in men. Metabolism 41: 1242-1248

49. McKeigue PM, Laws A, Chen YD, Marmot MG, Reaven GM (1993) Relation of plasma triglyceride and apo B levels to insulin-mediated suppression of non esterified fatty acids. Arterioscler Thromb 13: 1187-1192

50. Kannel WB (1985) Lipids, diabetes and coronary heart disease: insights from the Framingham Study. Am Heart J 110: 1100-1107

51. Barrett-Connor EL, Cohn BA, Wingard DL, Edelstein SL (1991) Why is diabetes mellitus a stronger risk factor for fatal ischemic heart disease in women than in men? The Rancho Bernardo Study. JAMA 265: 627-631 